\title{
O SISTEMA ONLINE DISPUTE RESOLUTION EM EXECUÇÃO FISCAL: ARBITRAGEM TRIBUTÁRIA E JURISDIÇÃO SUSTENTÁVEL ${ }^{1}$
}

\author{
THE ONLINE DISPUTE RESOLUTION SYSTEM IN TAX EXECUTION CASES: \\ TAX ARBITRATION AND SUSTAINABLE JURISDICTION
}

\begin{abstract}
Magno Federici Gomes ${ }^{2}$
Escola Superior Dom Helder Câmara

Doutor em Direito

Coordenador e professor do Doutorado e Mestrado Acadêmico em Direito Ambiental e Desenvolvimento Sustentável na Escola Superior Dom Helder Câmara Belo Horizonte/MG/Brasil magnofederici@gmail.com
\end{abstract}

Alfonso Jaime Martínez Lazcano ${ }^{3}$ Universidad Autónoma de Chiapas Doutor em Direito Público Professor e Pesquisador no Centro de Estudos para a Construção da Cidadania e da Seguridade na Universidad Autónoma de Chiapas

Tuxtla Gutiérrez, Chiapas, México alfonso.martinez@unach.mx

Michele Alves de Carvalho ${ }^{4}$

IBMEC/Damásio Educacional Pós-graduanda em Direito Processual Civil Belo Horizonte/MG/Brasil michelealvescferreira@gmail.com

RESUMO: A execução fiscal regulamentada pela Lei $n^{\circ}$ 6.830/80 se mostrou eficiente até certo momento, mas passou a ser questionada por não ensejar o diálogo, apenas imposições e restrições sob o argumento de que o crédito é indisponível por ser de interesse público. Diante disso, surgiu uma nova corrente baseada na arbitragem com a finalidade de diminuir os

\footnotetext{
${ }^{1}$ Trabalho financiado pelo Edital 03/2020 da Escola Superior Dom Helder Câmara, resultante dos Grupos de Pesquisas (CNPQ): Responsabilidade Civil e Processo Ambiental (RECIPRO), NEGESP, Metamorfose Jurídica e CEDIS (FCT-PT).

${ }^{2}$ Estágio Pós-doutoral em Direito Público e Educação pela Universidade Nova de Lisboa-Portugal (Bolsa CAPES/BEX 3642/07-0). Estágios Pós-doutorais em Direito Civil e Processual Civil, Doutor em Direito e Mestre em Direito Processual, pela Universidad de Deusto-Espanha (Bolsa da Cátedra UNESCO e do Gobierno Vasco-Espanha). Mestre em Educação pela PUC Minas. Coordenador e Professor do Doutorado e Mestrado Acadêmico em Direito Ambiental e Desenvolvimento Sustentável na Escola Superior Dom Helder Câmara. Professor Titular licenciado da Faculdade de Direito Arnaldo Janssen. Advogado Sócio do Escritório Moraes \& Federici Advocacia Associada. Líder do Grupo de Pesquisa: Responsabilidade Civil e Processo Ambiental (RECIPRO)/CNPQ-BRA e integrante dos grupos: Centro de Investigação \& Desenvolvimento sobre Direito e Sociedade (CEDIS)/FCT-PT, Núcleo de Estudos sobre Gestão de Políticas Públicas (NEGESP)/CNPQ-BRA e Metamorfose Jurídica/CNPQ-BRA.

${ }^{3}$ Pós-doutor em Métodos de Resolução de Conflitos e Direitos Humanos pela Universidad Juárez Autónoma de Tabasco; Doutor em Direito Público pela Universidad del Sur; Mestre em Direito Constitucional e Garantias Constitucionais pela Universidad Autónoma de Chiapas e Graduado em Direito pela Universidad Nacional Autónoma del México (UNAM). Professor da pós graduação, graduação e pesquisador da Universidad Autónoma de Chiapas, no México; Professor honorário da Faculdade de Direito da UNAM. Presidente da Associação Latino-Americana de Advogados Processualistas; membro do Instituto Ibero-Americano de Direito Processual; vice-presidente em pesquisas científicas da Associação Mundial de Justiça Constitucional; da Associação Colombiana de Direito Processual Constitucional; da Associação Paraguaia de Direito Processual Constitucional e da Associação Argentina de Direito Processual Constitucional. Editor chefe da Revista Jurídica Primeira Instância. Advogado militante.

${ }^{4}$ Pós-Graduanda em Direito Processual Civil pela Damásio Educacional/Ibmec. Pós-Graduanda em Direito, Inovação e Tecnologia pelo Complexo de Ensino Renato Saraiva.
} 
GOMES, Magno Federici; MARTínEZ LAZCANO, Alfonso Jaime; CARVALHO, Michele Alves de. O sistema Online Dispute Resolution em execução fiscal: arbitragem tributária e jurisdição sustentável

processos no Poder Judiciário e para tanto, adotou-se como base de estudo a plataforma Online Dispute Resolution (ODR) em outros países, com a finalidade de promover uma prestação jurisdicional moderna e tornando-se novo meio de impugnação ao crédito tributário.

Palavras-chave: resolução de disputas online; execução fiscal; jurisdição sustentável.

ABSTRACT: The regulated tax execution by Law $n^{\circ} 6.830 / 80$ proved to be efficient up to a certain point, but started to be questioned for not leading to dialogue, only impositions and restrictions under the argument that credit is unavailable because it is in the public interest. Therefore, a new trend based on arbitration emerged in order to reduce lawsuits in the Judiciary and, for this purpose, the Online Dispute Resolution (ODR) platform in other countries was adopted as a study base, with the purpose of promoting a provision modern jurisdiction and becoming a new means of challenging tax credit.

Keywords: online dispute resolution; tax foreclosure; sustainable jurisdiction.

SUMÁRIO: 1 Introdução. 2 Sociedade líquida e a comunidade versus polis moderna e suas influências no sistema Online Dispute Resolution. 3 Surgimento da Online Dispute Resolution e seus precursores. 4 Autocomposição e os principais métodos alternativos de solução de conflitos. 5 A Execução fiscal versus a indisponibilidade do crédito tributário. 6 Online Dispute Resolution na execução fiscal: as vantagens da arbitragem tributária e o momento de sua instauração. 6.1 Vantagens da arbitragem tributária .6.2 Existe momento adequado para a instauração da arbitragem tributária? 7 Avanços legislativos necessários e edição de Lei Complementar versus Projeto de Lei $n^{\circ}$ 4.257/19. 8 Programa online arbitral. 9 Considerações finais. Referências.

Para citar este artigo (ABNT NBR 6023:2018)

GOMES, Magno Federici; MARTÍNEZ LAZCANO, Alfonso Jaime; CARVALHO, Michele Alves de. O sistema Online Dispute Resolution em execução fiscal: arbitragem tributária e jurisdição sustentável. Revista Thesis Juris - RTJ, São Paulo, v. 10, n. 2, p. 317-337, jul./dez. 2021. http://doi.org/10.5585/rtj.v10i2.19448.

\section{INTRODUÇÃO}

O Poder Judiciário brasileiro realiza a tutela jurisdicional de forma obstaculizada, sendo os de execução fiscal um dentre aqueles que ocupam maior número nas prateleiras e isso faz com que haja um debate atual e necessário sobre a possibilidade de submeter esses processos à arbitragem, carreando menor quantitativo de lides e uma melhora na qualidade e eficiência do procedimento de execução.

A partir desse debate, prestou-se ao exame da possibilidade de ocorrer arbitramento do crédito tributário observando o princípio da legalidade e demais princípios da Administração 
GOMES, Magno Federici; MARTíneZ LAZCANO, Alfonso Jaime; CARVALHO, Michele Alves de. O sistema Online Dispute Resolution em execução fiscal: arbitragem tributária e jurisdição sustentável

Pública para que esse meio alternativo seja viável através do sistema Online Dispute Resolution (ODR), visto que outros países já consolidaram essa plataforma.

Por fim, a presente pesquisa visa analisar o Projeto de Lei (PL) $\mathrm{n}^{\circ} 4.257 / 19$, fazendo as devidas ressalvas em relação ao processo e a possibilidade de inserção no texto sobre a previsão do trâmite ocorrer via sistema ODR.

O método utilizado foi o teórico documental com técnica dedutiva, com análise bibliográfica, legal e jurisprudencial, bem como pesquisa histórica em sites e leitura de teses e artigos acadêmicos, sendo que o marco teórico da pesquisa foram as obras de Priscila Faricelli de Mendonça (2014) e Ethan Katsh, Janet Rifkin e Alan Gaitenby (2000).

Para alcançar o objetivo proposto, a pesquisa foi dividida em cinco capítulos, sendo que no primeiro a discussão se concentra na evolução da sociedade, passando pela $4^{\text {a }}$ (quarta) Revolução Industrial até a modernidade líquida; o segundo capítulo trouxe a perspectiva do que é o sistema ODR e como se originou, analisando sua influência em alguns países, inclusive no Brasil; o terceiro capítulo expõe a autocomposição e sua consolidação após a criação da EC n $^{\circ}$ 45 e do CNJ; No quarto capítulo se discute o crédito tributário e sua correlação com o Princípio da Indisponibilidade do Interesse Público e por fim, o quinto capítulo convergiu às ideias supra e fez uma ligação entre a execução fiscal e o sistema ODR, elencando as vantagens de se utilizar a arbitragem e qual o melhor momento para sua instauração. Entretanto, alguns questionamentos foram levantados e, nesse ínterim, houve a análise do Projeto de Lei $\mathrm{n}^{\mathrm{o}}$ 4.257/19.

\section{SOCIEDADE LÍQUIDA E A COMUNIDADE VERSUS POLIS MODERNA E SUAS INFLUENCIAS NO SISTEMA ONLINE DISPUTE RESOLUTION}

Os liberais pós-iluministas acolhiam o pensamento de que as diferenças nasciam quando a razão não estava desperta ou havia voltado a se recolher, sendo corroborada posteriormente pelos liberais que perceberam que antes mesmo dos homens começarem a criar seus próprios códigos de conduta ou regras, eles já se encontravam unidos por dois aspectos trazidos por seus antecessores: a história e os costumes.

No livro Modernidade Líquida, seu autor afirma que "em termos sociológicos, o comunitarismo é uma reação esperável à acelerada 'liquefação' da vida moderna" (BAUMAN, 2001, p. 195), assentando essa afirmação no desequilíbrio entre liberdade e garantias individuais, corroborando, assim com a assertiva de que as antigas garantias desapareçam e em seu lugar se encontre a finitude e brevidade dos laços humanos. 
GOMES, Magno Federici; MARTínEZ LAZCANO, Alfonso Jaime; CARVALHO, Michele Alves de. O sistema Online Dispute Resolution em execução fiscal: arbitragem tributária e jurisdição sustentável

Ademais, a comunidade não é apresentada como uma escolha dentre diversas outras já que ela se impõe de tal maneira que cabe participar dela ou não ser nada (BAUMAN, 2001, p. 198).

A comunidade plural é a única compatível com a modernidade líquida por ser crível e pragmática e dessa forma, para que haja a manutenção dessa sociedade que se acomoda e reacomoda com extrema facilidade, é necessário que haja indivíduos que sejam determinados para lutar pela sua unidade e para mantê-la.

As pessoas que aceitaram essa pluralidade perceberam que viver juntos demanda consenso e em comunidades que continuam existindo devido a freios e contrapesos, essa balança é necessária para não ocorrer supressão de direitos e coercibilidade, tornando o diálogo um meio para se chegar ao fim de uma discussão.

Diante desse cenário, aqueles nascidos na era da liquefação perceberam que aquele modelo que a priori conheciam da execução tributária se assentava na verdade em bases coercitivas. Visando a alteração desse modelo, pretende-se seguir o protótipo de outros países que se utilizam da arbitragem para dirimir conflitos.

Apesar dos meios alternativos de conflitos ainda se encontrarem em segundo plano em relação ao Poder Judiciário, há um movimento que vem inserindo-os no centro da lide enfrentada pelas partes.

Diante desse cenário, verifica-se que muitas empresas voltadas à área de tecnologia vêm investindo nesse ramo, culminando nas ODR's, que preponderantemente são plataformas e, através do diálogo e negociação de interesses, tenta-se encontrar um consenso que é aquele que une os indivíduos plurais da sociedade líquida.

\section{SURGIMENTO DA ONLINE DISPUTE RESOLUTION E SEUS PRECURSORES}

Com a criação dos Estados democráticos, houve a necessidade de que os indivíduos se comportassem, surgindo, então, o Poder Judiciário, que utiliza o Direito como um mecanismo de pacificação social. Contudo, as sociedades atingiram um alto grau de complexidade e o Estado-Juiz passou a ser reconhecido pela lentidão e burocracia.

Nesse sentido, tornou-se necessária à criação e ampliação de mecanismos alternativos para solucionar os conflitos que pudessem superar a morosidade sem perder a qualidade que é inerente ao Judiciário porquanto:

É inaceitável permitir e coadunar com a morosidade do Poder Judiciário na entrega da tutela jurisdicional, pois, além de evidenciar a impotência do Estado no que tange à resolução de conflitos e à evidente falta de aplicação de um processo justo, mitiga o próprio acesso à jurisdição (GOMES; FERREIRA, 2017, p. 109). 
GOMES, Magno Federici; MARTÍNEZ LAZCANO, Alfonso Jaime; CARVALHO, Michele Alves de. O sistema Online Dispute Resolution em execução fiscal: arbitragem tributária e jurisdição sustentável

Os pioneiros do sistema ODR foram Ethan Katsh e Janet Rifkin, com a criação do Centro Nacional para Tecnologia e Resolução de Disputas (CNTRD), com auxílio da Universidade de Massachussets, fomentando a tecnologia da informação e gerenciando conflitos. Após escreverem um livro sobre o tema, inúmeras instituições passaram a examinar o programa, como, por exemplo, a Organização Mundial de Propriedade Intelectual (OMPI), e a Conferência de Haia sobre Direito Internacional Privado (HCCH) (AB2L..., 2017, s. p.).

No ano de 1995, a plataforma $e B a y$ foi projetada por Pierre Omidyars, engenheiro de softwares e o intuito de Pierre era criar um leilão online. Contudo, diferente das relações que foram estabelecidas anteriormente, quando o comércio era físico, na plataforma $e B a y$, a maioria dos fornecedores e compradores não mantém nenhum vínculo, uma vez que:

\footnotetext{
Embora existam contextos tradicionais de mediação, como disputas de consumidores e comerciantes em que as partes não tenham um relacionamento prévio e não antecipem um futuro, as disputas que surgem no contexto do eBay são particularmente "sem relações. " Esses compradores e vendedores - muitas vezes se envolveram apenas na transação que está sendo contestada. Nem esses compradores e vendedores normalmente antecipam que terão um relacionamento comercial futuro (KATSH; RIFKIN; GAITENBY, 2000, p. 714 tradução nossa) ${ }^{5}$.
}

A plataforma Ebay é responsável por sessenta milhões de disputas por ano, tornando-se uma plataforma eficiente e ao mesmo tempo de baixo custo, visto que evita a propositura excessiva de ações, bem como gastos com advogados e deslocamento (ONLINE..., 2017, s. p.).

A criação da Agenda 2030, da Organização das Nações Unidas (ONU), trouxe como um de seus objetivos a construção de sociedades pacíficas, justas e inclusivas, respeitando os Direitos Humanos, da justiça e da igualdade. Nesse panorama, o sistema ODR possibilita a resolução de conflitos transnacionais se alinhando e consagrando o Objetivo de Desenvolvimento Sustentável (ODS) correlacionado a justiça e instituições eficazes, possibilitando uma tomada de decisão, tornando-se inclusivo e fomentando a participação através do diálogo.

Em torno desse cenário diversos países vêm investindo de forma incisiva na informatização do Judiciário, como é o caso do sistema norte americano.

O programa Modria projetado por Colin Rule em 2011, funciona dentro do eBay e do PayPal, possibilitando a solução de conflito entre as partes através da tomada de decisão das mesmas e, caso haja divergências, há a intervenção de um terceiro.

\footnotetext{
${ }^{5}$ Tradução livre de: "While there are certain traditional contexts for mediation, such as consumer and merchant disputes in which the parties do not have a prior relationship and do not anticipate a future one, the disputes that arise in the context of eBay are particularly "relationshipless." These buyers and sellers often have engaged in only the transaction that is being contested. Nor do these buyers and sellers typically anticipate that they will have a future commercial relationship" (KATSH, RIFKIN, GAITENBY, 2000, p. 714).
} 
GOMES, Magno Federici; MARTÍNEZ LAZCANO, Alfonso Jaime; CARVALHO, Michele Alves de. O sistema Online Dispute Resolution em execução fiscal: arbitragem tributária e jurisdição sustentável

Após a criação da União Europeia (UE), foram instituídas, a Diretiva 2013/2011 ou "Diretiva ADR" e o Regulamento 524/2013 para eliminar os protocolos criados pelos países membros a livre movimentação de mercadorias em seu interior, possibilitando a abertura do mercado dessa comunidade. Através do Regulamento no 524/2013, em 2015, criou-se a Plataforma ODR para a UE, local onde se concentram as demandas.

O Reino Unido criou o HMOC para a solução de conflitos online do Conselho de Justiça em causas cujo valor era inferior a $£ 25$ mil e teria três funções: classificar a demanda; recomendar um dos métodos de resolução de conflitos e, na terceira fase, o "Juiz online" entraria para decidir a lide e findar a disputa.

No Brasil, a instauração das ODR's ocorreu de maneira lenta e atrasada em relação a outros países. Atualmente, elas vêm tendo nicho através da $A B 2 L$ e, segundo pesquisa feita por essa associação, o requerimento por plataformas como ODR's são de irrisórios 2\% (AB2L..., 2017, s. p.).

O ínfimo número supracitado está relacionado à falta de informação em relação à existência dessas startups $^{6}$, por ser ainda um meio desconhecido e o alto custo para a criação da plataforma, que demanda tecnologia de ponta.

De acordo com pesquisa feita pela Fundação Getúlio Vargas (FGV), entre os anos de 2006 a 2012, a quantidade de processos relacionados às questões de consumo aumentaram em quatro vezes no Supremo Tribunal Federal (STF) (SUPREMO..., 2013, s. p.) e, devido a essa demanda criou-se a Plataforma Sem Processo e o site e-Conciliar.

A plataforma Sem processo contém dois módulos. No primeiro, o advogado insere os documentos e a plataforma os envia para a empresa que figura no polo oposto, possibilitando um acordo antes do ajuizamento e na fase contenciosa, o advogado insere no site casos idênticos àquele que será tratado e a empresa é notificada de imediato, criando-se um chat para dialogarem, sendo que se houver um acordo, é gerado um título executivo extrajudicial.

O site e-Conciliar foi inaugurado em 2017 pelo Procurador do estado do Ceará Vicente Braga e tem como objetivo primário a busca pela cooperação com o Estado em parte do dever de jurisdição e como objetivo secundário a resolução de acordos que estão ainda na fase de postulação no Poder Judiciário, gerando ao final, um termo de acordo extrajudicial. Ressalta-se que a plataforma só recebe casos através do cadastro da $\mathrm{OAB}$ dos advogados, tornando-os seus parceiros e público-alvo, almejando ofertar uma defesa técnica de qualidade, tutelando melhor os interesses do cliente.

\footnotetext{
${ }^{6}$ Empresas emergentes que foram criadas recentemente e que possuem como objetivo a criação ou aprimoramento de um modelo de negócios no qual possam desenvolver um protótipo repetível, gerando valor para seus clientes.
} 
GOMES, Magno Federici; MARTÍNEZ LAZCANO, Alfonso Jaime; CARVALHO, Michele

Alves de. O sistema Online Dispute Resolution em execução fiscal: arbitragem tributária e jurisdição sustentável

O programa é financiado através da cobrança de uma comissão de $20 \%$ sobre o valor que a parte requerida pagar descontando o valor que a requerente aceita receber, tornando viáveis os acordos de grande monta e tornando a plataforma atrativa.

Diante de inúmeras plataformas que já existem e daquelas que estão eminentemente a ponto de surgir, questiona-se quais delas seriam melhores, se as governamentais ou as privadas e baseando-se nos estudos feitos ao longo dessa pesquisa, constatou-se que são essas últimas, porque, as inovações tecnológicas criadas pela iniciativa privada têm enorme potencial para fazer as partes unirem forças para resolverem a lide sem empreender grandes esforços como ter que se submeter a possível licitação e maior decurso de tempo para se efetivar o programa ${ }^{7}$.

Ademais, não seria necessário o envio de propostas as audiências prévias a instrução do processo, fomentando as grandes empresas litigantes a buscar tais programas. Visando a busca por celeridade e percebendo que a iniciativa privada já tomou as rédeas desses programas, o Governo Federal, buscando ofertar celeridade a população, aderiu à plataforma internacional de fraudes e golpes relacionados ao comércio eletrônico à Econsumer.

Para tanto, o SENACON, ligado ao Ministério da Justiça, firmou acordo em cerimônia virtual, fazendo com que a plataforma econsumer.gov, de iniciativa do ICPEN (International Consumer Protection and Enforcement Netword) permita que o consumidor faça denúncias online de fraudes internacionais na internet, mostrando-se notável essa iniciativa, posto que dá enfoque ao princípio da eficiência na prestação de serviços públicos, atualizando-se para se incorporar as novas tecnologias para colocá-las à disposição dos usuários.

\section{AUTOCOMPOSIÇÃO E OS PRINCIPAIS MÉTODOS ALTERNATIVOS DE SOLUÇÃO DE CONFLITOS}

A jurisdição tal qual conhecemos vem modificando-se e o embate entre celeridade processual e segurança jurídica aumentou, sendo que o Código de Processo Civil de 2015 (CPC/15) foi criado com o intuito de dar destaque aos novos métodos de resolução de conflitos, consagrando-os em seu texto.

O Poder Judiciário, a partir da Emenda no 45/2004, criou o CNJ, sendo inserido na Constituição da República de 1988 (CR/88) em seus arts. 92 e 103-B, que outorgaram ao CNJ as funções correcionais, normativas e estatísticas, além de lhe atribuir três atividades: controlar a atuação administrativa e a área financeira do Poder Judiciário e realizar a fiscalização do descumprimento dos deveres relacionados à função dos juízes.

\footnotetext{
${ }^{7}$ Para outro panorama sobre as plataformas particulares e públicas de ODR's e sua utilização, ver: GOMES; CABRAL; RIBEIRO, 2021, p. 136-151.
} 
GOMES, Magno Federici; MARTínEZ LAZCANO, Alfonso Jaime; CARVALHO, Michele Alves de. O sistema Online Dispute Resolution em execução fiscal: arbitragem tributária e jurisdição sustentável

O CPC/15, em seu art. 334, §7º , e o próprio CNJ, através da Resolução n ${ }^{\circ} 125$ (artigo $3^{\circ}$, alterado pela Emenda $n^{\circ} 02$ ), fomenta a adoção de meios alternativos de disputas através das ODR's, possibilitando parcerias entre o setor público-privado.

De acordo com o relatório "Justiça em Número", para cada nove processos ajuizados, somente três processos antigos tinham um desfecho, acrescendo-se ao acervo dos 93 milhões de processos que se encontram pendentes de julgamento (BRASIL, 2017, p. 148).

A conciliação é um método que objetiva o desenlace de conflitos mais simples, no qual uma terceira pessoa imparcial (conciliador) pode intervir no problema e ter uma atitude mais ativa dentro do conflito.

A mediação é um método preambular e consensual de resolução de conflitos, todavia, é mais utilizada em casos complexos, sendo que o mediador tem o papel de auxiliar a comunicação para se chegar a um consenso, sendo imparcial.

Nesse ínterim, o parágrafo $3^{\circ}$ do art. 165 do CPC/15, deixa expresso que as partes terão papel essencial para a resolução do imbróglio, devendo identificar as soluções do conflito que resultem em benefício para ambas, baseando-se na ideia de comunicação não violenta desenvolvida por Rosenberg.

De acordo com o portal do CNJ, “As duas técnicas são norteadas por princípios como informalidade, simplicidade, economia processual, celeridade, oralidade e flexibilidade processual” (BRASIL, 2017, p. 104). Ambas as técnicas se pautam pelos princípios elencados na Resolução n ${ }^{\circ}$ 125/2010 do CNJ como, por exemplo, a confidencialidade, decisão informada, competência e imparcialidade, dentro outros.

A arbitragem foi criada pela Lei $n^{\circ}$. $9.307 / 96$ (com alterações feitas pela Lei $n^{\circ}$. 13.129/15), na qual as partes estarão vinculadas ao árbitro que dará uma decisão definitiva, o que possibilita a execução da sentença arbitral, impossibilitando recurso perante a instância superior.

A arbitragem se divide em três fases: a primeira é a convenção de arbitragem, na qual as partes exteriorizam suas vontades; na segunda, as partes firmam a cláusula compromissória que será feita a termo e, na terceira, é marcada pelo compromisso arbitral, documento que as partes declaram suas vontades em solucionar o litígio por meio da arbitragem.

É perceptível que a sociedade brasileira busca uma solução mais célere para seus problemas, fazendo com que o Estado passasse a enxergar positivamente a arbitragem, uma vez que além de ter menos formalismos, fornece rapidez na solução dos conflitos. 
GOMES, Magno Federici; MARTÍNEZ LAZCANO, Alfonso Jaime; CARVALHO, Michele Alves de. O sistema Online Dispute Resolution em execução fiscal: arbitragem tributária e jurisdição sustentável

O site Consumidor.gov, criado em 2014, se diferencia das demais startups por estar ligado ao governo por meio da constante verificação feita pela Secretaria Nacional do Consumidor (SENACON), permitindo que o próprio cliente realize reclamações no site.

Como o site é mantido pelo governo, as empresas que se interessarem na diminuição das lides consumeristas, terão sua reputação influenciada, tendo em vista que os resultados das demandas são convertidos em gráficos e tabelas.

Frisa-se que essa plataforma possui convênios com alguns órgãos, como por exemplo, PROCON'S, Ministérios Públicos Estaduais (MPEs), Defensorias Públicas (DPs) e Tribunais de Justiça (TJs), demonstrando que o Poder Público está atuando para uma maior satisfação nas relações consumeristas, fato que pode ser corroborado com os dados do próprio site, pois atualmente existem 1.884.860 pessoas e 659 empresas já cadastradas (BRASIL, 2020, s. p.).

Já a plataforma Juspro (Justiça sem processo) está ligada ao Tribunal de Justiça de São Paulo (TJSP). Ela oferta sessões de mediação e conciliação de forma online e presencial e, posteriormente, a realização de acordo, que será homologado pelo juiz. As pessoas e empresas agendam as audiências através do aplicativo, facilitando de forma inovadora o acesso ao programa.

O Centro Judiciário de Solução de Conflitos e Cidadania (CEJUSC) foi efetivado pelo CNJ por meio da Resolução $n^{\circ}$ 125/2010. Através dela, criou-se a Política Judiciária Nacional de Tratamento dos Conflitos de Interesses que aplicaram os meios alternativos para solucionar as contendas no âmbito de todo território brasileiro.

O CNJ determinou que os tribunais de todos os estados criassem Núcleos Permanentes de Métodos Consensuais de Solução de Conflitos (NUPEMECs), colocando em prática o que se preceitua no inciso XXXV do art. $5^{\circ}$ da $\mathrm{CR} / 88$, qual seja, livre acesso à justiça. Por sua vez, os tribunais deveriam criar o CEJUSC.

Necessário frisar que os CEJUSC'S tem dupla finalidade. Na fase pré-processual, diversas demandas se exaurem nesses Centros através do fomento do diálogo entre as partes. Já em fase processual, o CEJUSC é o local das audiências inaugurais dos casos que já se encontram em alguma Vara e, para que a mediação tomasse importância em um país que tem o costume de "judicializar", o legislador deixou expresso no parágrafo $8^{\circ}$ do art. 334 do CPC/15 que tal audiência é obrigatória e, caso alguma das partes de forma injustificada falte a essa conciliação, tal omissão será considerada ato atentatório à dignidade da justiça, pois essa se colocou à disposição do cidadão para escutá-lo e tentar dirimir a lide da forma mais célere possível, causando prejuízos ao erário, devendo a parte ressarci-lo. 
GOMES, Magno Federici; MARTínEZ LAZCANO, Alfonso Jaime; CARVALHO, Michele Alves de. O sistema Online Dispute Resolution em execução fiscal: arbitragem tributária e jurisdição sustentável

\section{A EXECUÇÃO FISCAL VERSUS A INDISPONIBILIDADE DO CRÉDITO TRIBUTÁRIO}

A execução fiscal regida pela Lei $n^{\circ}$ 6.830/80, realiza a expropriação de bens do contribuinte para satisfazer seus créditos junto à Fazenda, de certo que somente a Certidão da Dívida Ativa (CDA) é a autorizadora da execução por ser um título líquido, certo e exigível.

Ainda está arraigado na doutrina que "a indisponibilidade dos interesses públicos significa que, segundo interesses qualificados como próprio da coletividade - internos ao setor público -, não se encontram à livre disposição de quem quer que seja por inapropriáveis" (BANDEIRA DE MELLO, 2005, p. 62-63).

No meio tributário, o interesse público estaria interconectado ao interesse coletivo e ambos seriam antônimos de interesse fazendário, como salienta:

O Estado, em determinadas situações, terá interesse envolvido distinto daquele interesse que diz respeito à coletividade que por vezes representa. Ao Estado, não basta, desse modo, ser voltado à satisfação dos seus anseios institucionais e nas diversas esferas em que atua, o bem maior será o melhor atendimento ao interesse da coletividade (MENDONÇA, 2014, p. 32)

Nesta conjuntura, para obter uma melhor visão, deve-se averiguar o crédito tributário e sua natureza correlacionando-os ao interesse público.

Crédito tributário é o valor que se constitui após o lançamento, necessitando de três requisitos: previsão em lei, fato gerador e lançamento.

O Código Tributário Nacional (CTN) traz a definição de tributo da seguinte forma: "toda prestação pecuniária compulsória, em moeda ou cujo valor nela se possa exprimir, que não constitua sanção de ato ilícito, instituída em lei e cobrada mediante atividade administrativa plenamente vinculada" (BRASIL, 1966).

O legislador, no art. $3^{\circ}$ do CTN, diz que o tributo é uma prestação pecuniária, impondolhe um caráter estritamente patrimonial. É através desse caráter de patrimonialidade que a corrente arbitralista assenta suas justificativas para que o crédito tributário seja disponível.

O CTN traz expresso em seus arts. 151, 156, 171 e 180, formas de dispor do crédito tributário, sendo eles, a anistia, transação, remissão e até mesmo o parcelamento. Conquanto, não teria consonância a lei oportunizar que o Estado realize a renúncia do crédito tributário nas situações elencadas pelos dispositivos e, em relação à arbitragem, tratá-lo como instituto indisponível, mesmo que nos termos da lei. 
Nessa linha de pensamento, o Superior Tribunal de Justiça (STJ) julgou um caso no qual teve a oportunidade de solucionar determinado conflito através da arbitragem, como se pode depreender da ementa:

EMENTA: Não só o uso da arbitragem não é defeso aos agentes da administração, como, antes é recomendável, posto que privilegia o interesse público [...] Ao optar pela arbitragem o contratante público não está transigindo com o interesse público, nem abrindo mão de instrumentos de defesa de interesses públicos, Está, sim, escolhendo uma forma mais expedita, ou um meio mais hábil, para a defesa do interesse público (STJ. MS 11.308/DF. Rel. Min. Luis Fux. Data de Julgamento: 09/04/08. DJe: 19/05/08).

Para analisar o presente julgado, parte-se do exame do art. 142 do CTN, que outorga a competência de compor o crédito tributário à autoridade administrativa que realizará o lançamento, procedimento administrativo que se torna apto a causar efeitos após a análise do fato gerador, tendo que determinar a matéria tributável, calcular o valor a ser pago e identificar o sujeito passivo.

Se a autoridade administrativa não realizar os atos de fiscalizar e arrecadar o crédito tributário, sofrerá consequências, como desvio de sua atividade funcional e desvio da coletividade por ser uma das finalidades da Administração pública. Portanto, o administrador público não pode se render a caprichos e se tornar omisso, tornando-a uma atividade vinculativa e indisponível por excelência, assim como se constata do art. $3^{\circ}$ do CTN.

Verifica-se que a atividade vinculada e indisponível do administrador público não se confunde com o crédito tributário que é disponível a partir de seu lançamento, pois não existe norma constitucional impondo óbice à arbitragem em matéria fiscal e o próprio CTN elenca os meios que o contribuinte pode realizar o pagamento, bem como ser perdoado. Isso torna a utilização desse meio eletivo de resolução de conflitos plenamente possível no meio fiscal para as lides que estão pendentes ou aplicá-lo preventivamente, visando a diminuição do acervo de $\operatorname{processos}^{8}$.

\section{ONLINE DISPUTE RESOLUTION NA EXECUÇÃO FISCAL: AS VANTAGENS DA ARBITRAGEM TRIBUTÁRIA E O MOMENTO DE SUA INSTAURAÇÃO}

A arbitragem entrega o litígio nas mãos de um terceiro qualificado, retirando a intervenção estatal, não se caracterizando como renúncia a direitos, mas na verdade, propõem uma resolução mais célere da questão.

\footnotetext{
${ }^{8}$ Não se olvida o advento da Lei no 13.988 , de 14 de abril de 2020, que autorizou a autocomposição por meio de "transação resolutiva de litígio relativo à cobrança de créditos da Fazenda Pública, de natureza tributária ou não tributária" (BRASIL, 2020 , art. $1^{\circ}$ ), no âmbito da União, suas autarquias e fundações, ratificando o art. 142 do CTN e a conclusão parcial dessa parte deste artigo.
} 
A controvérsia tributária posta sobre a seara arbitral não encontra óbice, pois o cunho pecuniário que o crédito tributário carrega se encontra dentro do contrato administrativo que possui caráter negocial e patrimonial, não havendo renúncia ou disposição de direitos como se depreende do AgRg no MS 11.308/DF, que diz:

EMENTA: Em verdade, não há que se negar a aplicabilidade do juízo arbitral em
litígios administrativos, em que presente direitos patrimoniais do Estado, mas ao
contrário, até mesmo incentivá-la, porquanto mais célere, nos termos do artigo 23 da
Lei $8987 / 95$, que dispõe acerca de concessões e permissões de serviços e obras
púbicas, que prevê em seu inciso XV, entre as cláusulas essenciais do contrato de
concessão de serviço público, as relativas ao 'foro e ao modo amigável de solução de
divergências contratuais.(STJ. MS 11.308/DF. Rel. Min. Luis Fux. Data de
Julgamento: $09 / 04 / 08$. DJe: $19 / 05 / 08$ ).

Como a discussão se funda na dicotomia entre direito público disponível e indisponível, sendo que o interesse público primário é a ideia de satisfação dos interesses da coletividade e, em contrapartida, o direito público secundário é a conexão que existe entre o Estado e a satisfação de seus próprios interesses, fica claro que a indisponibilidade do crédito tributário não é absoluta e que a sentença arbitral será fundada em lei.

\subsection{VANTAGENS DA ARBITRAGEM TRIBUTÁRIA}

Segundo dados obtidos pela Universidade de Londres através da Escola de Arbitragem Internacional Queen Mary, as vantagens da arbitragem em temática tributária seriam: exequibilidade dos laudos arbitrais; flexibilidade procedimental; possibilidade de escolha de árbitros; confidencialidade; neutralidade; definitividade das decisões; celeridade procedimental e custo (ESCOBAR, 2017, p. 53).

A viabilidade de se executar os laudos arbitrais dá enfoque ao direito tributário internacional e tornou-se comum que empresas tenham seu conjunto de bens e direitos em mais de um país, facilitando a execução de laudo arbitral estrangeiro.

A flexibilidade procedimental possibilita previsão contratual por meio de cláusula arbitral ou compromisso arbitral mesmo antes do início do conflito, adaptando-se as regras conforme a preferência das partes.

A possibilidade de seleção de árbitros é característica diferencial e como preceitua o art. 13 da Lei de Arbitragem, existem os requisitos de que detenham confiança das partes e que possuam capacidade, não obstaculizando a nomeação de árbitros especializados em contabilidade, principalmente se o assunto a ser versado for de direito tributário. 
GOMES, Magno Federici; MARTíneZ LAZCANO, Alfonso Jaime; CARVALHO, Michele Alves de. O sistema Online Dispute Resolution em execução fiscal: arbitragem tributária e jurisdição sustentável

A confidencialidade deve ser afastada visando o cumprimento do art. 37 da CR/88 e caminhando nessa mesma orientação, a Lei 13.129/15 inseriu o $\S^{\circ}$ ao art. $2^{\circ}$ da Lei de Arbitragem dispondo que "A arbitragem poderá ser de direito ou de equidade, a critério das partes. [...] $\S 3^{\circ} \mathrm{A}$ arbitragem que envolva a administração pública será sempre de direito e respeitará o princípio da publicidade" (BRASIL, 2015).

Nesse ínterim, observa-se que:

\begin{abstract}
Apesar da publicidade ser obrigatória em matéria arbitral tributária, não existe obstáculos que distanciam a viabilidade desse procedimento envolvendo matéria da administração pública, defendendo que o sigilo nas arbitragens que versam sobre assuntos privados pode ser dispensado pelas partes em comum acordo, excetuando aqueles casos expressamente previstos no art. 189 do Código de Processo Civil de 2015 (MENDONÇA, 2014, p. 129).
\end{abstract}

A neutralidade não se amolda ao procedimento porque significa ser indiferente. Em contrapartida, a imparcialidade significa não fornecer vantagens, se enquadrando como princípio de acordo com o art. $21, \S 2^{\circ}$ da Lei de Arbitragem.

A definitividade das decisões diz respeito à inapelabilidade das sentenças arbitrais, pois alcançará tanto o fisco como o contribuinte, tornando o mérito da decisão não passível de revisão perante o Poder Judiciário, salvo nos casos de anulabilidade comprovada, violando os arts. 12 III; $21 \S 2^{\circ}, 26$ e 32 da Lei de Arbitragem.

A celeridade é uma inovação trazida pela EC no 45/2004, em seu art. 5, LXXVIII, porém, não está sendo cumprida nas execuções fiscais em território nacional.

Ademais, o fator custo deve ser observado junto ao fator tempo, porque o processo, se submetido a tais câmaras, demorarão menos tempo para serem resolvidos.

Por fim, torna-se necessário ratificar a ideia de que devem ser observados os princípios processuais constitucionais, mas também deve haver uma especial atenção aos princípios específicos da arbitragem tributária, que estão elencados no art. $21, \S 2^{\circ}$ da Lei de Arbitragem.

\title{
6.2 EXISTE MOMENTO ADEQUADO PARA A INSTAURAÇÃO DA ARBITRAGEM TRIBUTÁRIA?
}

O método de consulta fiscal viabiliza a interlocução entre o fisco e o contribuinte. Contudo, mesmo possuindo vinculação entre as partes, esse método ainda não é transparente por ser feito somente pela administração tributária.

Diante desses fatores, existe a possibilidade da arbitragem se instaurar em momento antecedente à constituição do crédito tributário, mas em contrapartida, nada obsta a instauração 
GOMES, Magno Federici; MARTínEZ LAZCANO, Alfonso Jaime; CARVALHO, Michele Alves de. O sistema Online Dispute Resolution em execução fiscal: arbitragem tributária e jurisdição sustentável

desse método alternativo durante o curso de processo administrativo e judicial, como será analisado a seguir.

Como já previsto no art. 38 da Lei de Execução Fiscal (LEF), quando se questiona o crédito tributário por meio de via judicial renuncia-se a esfera administrativa e, feita à devida analogia, constata-se que a escolha pela via arbitral também importa na renúncia pela via judicial.

Entretanto, ao instaurar o procedimento quando a execução já se encontra em curso, a renúncia à arbitragem seria o melhor caminho a ser seguido, posto que, se as partes optarem pela via arbitral enquanto o processo corre, necessitariam de compromisso arbitral na modalidade judicial feito por termo nos autos na presença do juízo ou tribunal onde corre a demanda, visto que é uma convenção bilateral no qual as partes renunciam a jurisdição estatal por acharem que a submissão do conflito ao árbitro será melhor, cessando a função do juiz togado.

Ademais, optando pelo compromisso arbitral, as partes não poderão se arrepender e posteriormente extinguir o compromisso arbitral com o intuito de ingressar na via judicial para rediscutir o assunto, posto que a sentença arbitral é irrecorrível, tornando-se um título executivo judicial e só pode ser anulada naqueles casos taxativos dos arts. 12 III; 21 §2 26 e 32 da Lei de Arbitragem.

Diante da necessidade de análise técnica, é necessária uma análise aprofundada do instituto central da lide. Nesse ponto, muitos dos que atuam no ramo fazendário não se especializaram em assuntos tributários, sendo em sua maioria servidores que foram promovidos para outra vara que se encarregava de processos distintos, acarretando procedimentos lentos, bem como em tomadas de decisão desinteligentes e devido a isso, faz-se necessário analisar a situação de Portugal,

Para atuarem como árbitros, seria interessante profissionais com tempo de experiência profissional na área do direito tributário. Na Arbitragem Tributária em Portugal exigese dez anos de experiência profissional, comprovando ser aposentado da magistratura, advogado, consultor e jurisconsultoria, professor de ensino superior em direito tributário ou de investigação científica, profissional a serviço da administração tributária ou que possui trabalhos científicos relevantes para o âmbito tributário (PASSINATO, 2019, p. 8-9).

Portanto, diante do princípio fundamental da legalidade, torna-se necessário que haja compromisso arbitral fundado em lei, devendo pactuar os procedimentos de forma escrita, sob pena de violação à formalidade conferida aos assuntos tributários no Brasil. 
GOMES, Magno Federici; MARTíneZ LAZCANO, Alfonso Jaime; CARVALHO, Michele

Alves de. O sistema Online Dispute Resolution em execução fiscal: arbitragem tributária e jurisdição sustentável

\section{AVANÇOS LEGISLATIVOS NECESSÁRIOS E EDIÇÃO DE LEI COMPLEMENTAR VERSUS PROJETO DE LEI Nº 4.257/19}

O grande, senão o principal, desafio dos governos na atualidade é recuperar o crédito público advindo da enorme divergência entre as despesas e as receitas públicas, essas em sua maioria advindas da tributação.

Para tanto, é necessário certa desburocratização para que as execuções fiscais no Brasil sejam mais céleres e eficazes, posto que no relatório "Justiça em Números", do CNJ, com ano base de 2017, constatou-se que o Poder Judiciário brasileiro contava com 80,1 milhões de processos pendentes de baixa no final de 2017, sendo que mais da metade desses processos (53\%) se referia à fase de execução (BRASIL, 2018, p. 121).

É notório que o sistema normativo não é completo, uma vez que não consegue prever todos os acontecimentos, fazendo com que surgissem lacunas não intencionais e posteriores no ordenamento jurídico.

Em análise a criação da LEF e a inserção da arbitragem em matéria de execução fiscal, percebe-se que não há necessidade de edição de nova lei complementar, uma vez que a arbitragem é um aspecto processual que seria inserido através de lege ferenda.

De autoria do Senador Antônio Anastasia, começou a tramitação do PL nº 4257 de 2019, que pretende modificar a LEF para ocorrer à execução fiscal extrajudicial e instituir a arbitragem tributária. No entanto, a proposta apresentada, apesar de ser digna de elogios, merece algumas considerações.

De início, no art. 16-A do PL no 4.257/19, observa-se que o legislador quis impor uma garantia à Administração Pública para que a arbitragem fosse realizada. Dessa forma, o executado deverá garantir a execução através de depósito em dinheiro, fiança bancária ou seguro garantia para optar pelo julgamento através do juízo arbitral que será o competente para julgar os embargos opostos em momento anterior.

Entretanto, discorda-se, pois é de se considerar que a Administração Pública está visando precipuamente o pagamento da dívida, tendo como objetivo o de se esquivar de procedimentos como busca e alienação de bens.

Percebe-se que a imposição das referidas garantias é uma restrição ao poder de escolha do cidadão e fere o Princípio da Isonomia elencado no art. 150, II da CR/88, tratando-os de forma desigual em situações parecidas, e, por isso, a LEF possibilita o contribuinte garantir o juízo de outras formas, como através da nomeação de bens de terceiro a penhora. Dessa forma, 
GOMES, Magno Federici; MARTínEZ LAZCANO, Alfonso Jaime; CARVALHO, Michele Alves de. O sistema Online Dispute Resolution em execução fiscal: arbitragem tributária e jurisdição sustentável

é necessário então que o legislador possibilite a garantia do juízo em qualquer das hipóteses elencadas no art. $9^{\circ}$ da LEF para ocorrer à arbitragem.

Ademais, em relação aos embargos à execução, o procedimento arbitral só poderá ser instaurado após processo de execução fiscal, ideia que se mostra contrário aquilo defendido em linhas anteriores. Isso porque a arbitragem teria melhores resultados se proposta em momento anterior a execução, tendo maior chance de se obter um acordo entre as partes.

Contudo, se já existir uma execução judicial, nada deveria impedir a possibilidade do arbitramento, porque é direito do cidadão saber quais os meios que ele dispõe e como funcionam, optando por aquele que reputa mais adequado.

Observa-se que o art. 16-B não especifica o árbitro com maior rigor, deixando vago esse aspecto. Considera-se que as partes deveriam eleger os árbitros dentre aqueles inscritos em lista, com vasta experiência, além de se exigir uma quantidade mínima de anos trabalhados.

Faz-se necessário analisar também o art. 16-C, reconhecendo que seria imprescindível que o PL elencasse os princípios basilares da arbitragem em matéria de execução fiscal, além de deixar claro que a publicidade se faz necessária, como preceitua o art. 37 da CR/88.

Ademais, no texto legislativo não constam mais princípios e por isso é necessária à inclusão daquelas vantagens já expostas em capítulo anterior, quais sejam, exequibilidade dos laudos arbitrais, flexibilização do procedimento a cada caso, possibilidade de escolha dos árbitros e imparcialidade dos mesmos, decisões definitivas, posto que não seja possível a revisão pelo Poder Judiciário, celeridade e custo, sendo esse último tratado de forma sucinta nos art. 16-D, caput e parágrafo único, e art. 16-E.

Ademais, insta reafirmar que o legislador deveria elencar no texto do PL os princípios da Lei de Arbitragem: contraditório, igualdade das partes, da imparcialidade do árbitro e de seu livre convencimento, deixando explícita a necessidade de segui-los por se tratar de princípios elencados em norma geral.

Ao tratar de valores da dívida tributária, recomenda-se que o legislador estipule um valor mínimo e máximo como parâmetros a serem fixados para a arbitragem ter eficácia, porque o objetivo da lei deve ser exaurir o Poder Judiciário dos milhões de casos de execução fiscal para assegurar o cumprimento do procedimento extrajudicial.

Nesse ínterim, insta salienta que quando a Fazenda Pública for parte no processo de execução fiscal, a remessa necessária deve ser observada por ser prerrogativa processual, sendo que o $\S 3^{\circ}$ do art. 496 do CPC/15 deixa expresso que não haverá remessa quando a condenação ou o proveito obtido na causa for inferior a mil salários-mínimos para o âmbito federal, de 
GOMES, Magno Federici; MARTíneZ LAZCANO, Alfonso Jaime; CARVALHO, Michele Alves de. O sistema Online Dispute Resolution em execução fiscal: arbitragem tributária e jurisdição sustentável

quinhentos salários-mínimos para o âmbito estadual e para os Municípios que forem capitais dos Estados e cem salários-mínimos para os demais Municípios.

Além de tais valores, deve-se observar no $\$ 4^{\circ}$ do art. 496 do CPC/15 que não haverá duplo grau de jurisdição obrigatório quando a decisão for baseada em súmula de tribunal superior, acórdãos do STF e do STJ em casos de recursos repetitivos ou de assunção de competência.

Nesse tocante, primando pela busca da celeridade processual, o $\mathrm{CPC} / 15$ diminuiu de forma considerável as possibilidades em que o a remessa necessária será utilizada, evitando-se recursos desnecessários e visando a concretização de forças dos tribunais superiores em questões de maior relevância.

\section{PROGRAMA ONLINE ARBITRAL}

A construção de um suporte de negociação inteligente teria um impacto decisivo na ordem jurídica interna, pois possibilitaria a resolução de conflitos sem submeter a lide ao judiciário, acarretando uma diminuição considerável do acervo de processos e, em segundo lugar, não desconsideraria o ordenamento jurídico, visto que as tratativas seriam baseadas em leis e demais normas infra legais e o procedimento seria acompanhado por um árbitro que estaria vinculado a um tribunal arbitral, não ensejando a feitura de contratos firmados entre as partes sem que se observem os preceitos legais.

Entretanto, a criação desse suporte online se encontra obstaculizado pela recusa que os indivíduos têm em submeter questões cruciais de suas vidas a uma plataforma, porém, tal receio é infundado, visto que a utilização da ODR como meio tecnológico tem a função de auxiliar as decisões que serão tomadas pelas partes, facilitando o diálogo e possibilitando uma resolução mais célere do problema, nesse sentido:

\footnotetext{
A tecnologia opera aqui essencialmente como um meio de comunicação. As partes em litígio poderão estar em diferentes e bem distanciadas localizações físicas, tal como um eventual mediador ou árbitro, mas todos eles com possibilidades de comunicação através das redes telemáticas. Neste modelo, as tecnologias não desempenharão um papel ativo, mas atuarão como facilitadoras do processo de resolução do litígio (ANDRADE, CARNEIRO, NOVAIS, 2010, p. 2-3).
}

Torna-se necessária então, a criação de uma plataforma com o cadastramento de todos os tribunais do país e com a inserção dos árbitros qualificados no sistema para que ocorra o sorteio de qual unidade irá realizar as tratativas. Em uma segunda fase, as partes poderão expor suas razões e tentar chegar a um consenso, enquanto o arbitro tem papel fundamental de explicar 
GOMES, Magno Federici; MARTínEZ LAZCANO, Alfonso Jaime; CARVALHO, Michele Alves de. O sistema Online Dispute Resolution em execução fiscal: arbitragem tributária e jurisdição sustentável

o procedimento e evidenciar os motivos pelos quais a arbitragem é mais vantajosa em relação a via judicial.

Caso não haja um acordo, o árbitro deverá informar como as partes deverão prosseguir, porém, se o acordo tiver sido firmado, será lavrado eletronicamente um termo constando o que fora explicitado durante a sessão de arbitragem e tendo o laudo arbitral a característica de ser exequível.

\section{CONSIDERAÇÕES FINAIS}

À luz do exposto ao longo do presente trabalho, conclui-se que a arbitragem em processos de execução fiscal, via sistema ODR, é um instrumento forte de pacificação social em meio à modernidade líquida, possibilitando o diálogo entre fisco e contribuinte ou responsável legal, na medida em que se torna novo meio de impugnação ao crédito tributário, de forma a acarretar a diminuição significativa do quantitativo de processos que obstruem o Poder Judiciário.

Nesse sentido, o sistema ODR possibilitaria a realização das negociações independente de onde tiver surgido o crédito tributário, porque, no Brasil, país extenso e com grande fluxo de pessoas, isso facilitaria uma solução pautada no diálogo mesmo estando às partes em locais diversos.

Ademais, salienta-se que a legislação tributária específica precisa se ajustar e evoluir, não havendo nesse caso a necessidade de edição de Lei Complementar. Para tanto, o PL n ${ }^{\circ}$ 4.257/19 que já está em tramitação, sendo caso específico de lege ferenda. Contudo, são necessárias alterações em seu texto, pois se deve estabelecer como parâmetro os países que já utilizam o sistema ODR em seus Tribunais e Cortes. Isso objetiva a realização de uma prestação jurisdicional moderna e faz com que a plataforma seja acessível aos usuários, bem como, permite a participação de mais pessoas em um mesmo tempo, visto que contará com a participação do arbitro.

Nesse sentido, é necessário que o fisco e os tribunais firmem parcerias com os grandes litigantes do país, dentre eles, o Estado e demais Entes Públicos, por serem os que mais possuem processos relacionados à execução fiscal, incentivando a utilização da plataforma online como procedimento para, em regra geral, ocorrer na fase pré-processual. Caso já exista execução em curso, deve-se informar à parte que a renúncia à via judicial importa na existência de compromisso arbitral na modalidade judicial, não podendo recorrer posteriormente à revisão no Poder Judiciário. 
GOMES, Magno Federici; MARTÍNEZ LAZCANO, Alfonso Jaime; CARVALHO, Michele Alves de. O sistema Online Dispute Resolution em execução fiscal: arbitragem tributária e jurisdição sustentável

Por fim, constata-se que o PL no $4.257 / 19$ possui lacunas e, para tanto, deverá estabelecer especificidades à arbitragem tributária por ser matéria relacionada à Administração Pública, como, por exemplo, elencar os princípios a serem seguidos, estipularem parâmetros monetários a fim de se estabelecer um valor máximo e mínimo da dívida, possibilitando ou não submissão a essa modalidade. Nesse sentido, vislumbra-se que houve cumprimento dos objetivos desse trabalho acadêmico.

\section{REFERÊNCIAS}

AB2L apresenta primeira pesquisa nacional sobre o cenário de lawtechs e legaltechs. Startupi, São Paulo, 13 jul. 2017. Disponível em: https://startupi.com.br/2017/07/ab21apresenta-primeira-pesquisa-nacional-sobre-o-cenario-de-lawtechs-e-legaltechs/. Acesso em: 23 fev. 2020.

ANDRADE, Francisco Carneiro Pacheco; CARNEIRO, Davide; NOVAIS, Paulo. A inteligência artificial na resolução de conflitos em linha. ScentiaI Juridica; Tomo LIX, $\mathrm{n}^{\circ}$ 321, 2010, p. 2-3. Disponível em: https://core.ac.uk/download/pdf/55619821.pdf. Acesso em: 17 de maio de 2020.

BANDEIRA DE MELLO, Celso Antônio. Curso de direito administrativo. 19. ed. São Paulo: Malheiros, 2005.

BAUMAN, Zygmunt. Modernidade líquida. Rio de Janeiro: Zahar, 2001.

BRASIL. Constituição da República Federativa do Brasil de 1988: Nós, representantes do povo brasileiro, reunidos em Assembléia Nacional Constituinte para instituir um Estado Democrático, destinado a assegurar o exercício dos direitos sociais e individuais. Brasília, DF: Presidência da República, 5 out. 1988. Disponível em:

http://www.planalto.gov.br/ccivil_03/constituicao/constituicaocompilado.htm. Acesso em: 07 abr. 2020.

BRASIL. Emenda Constitucional $\mathrm{n}^{\circ} 45$, de 30 de dezembro de 2004. Altera dispositivos dos arts. $5^{\circ}, 36,52,92,93,95,98,99,102,103,104,105,107,109,111,112,114,115,125,126$, 127, 128, 129, 134 e 168 da Constituição Federal, e acrescenta os arts. 103-A, 103B, 111-A e 130-A, e dá outras providências. Diário Oficial da União, Brasília, 31 de dezembro de 2004.

BRASIL. Justiça em Números 2017: ano base 2016. Conselho Nacional de Justiça, Brasília, 2017. Disponível em: https://www.cnj.jus.br/pesquisas-judiciarias/justica-em-numeros/.

Acesso em 30 mar. 2020.

BRASIL. Justiça em Números 2018: ano base 2017. Conselho Nacional de Justiça, Brasília, 2018. Disponível em: https://www.cnj.jus.br/pesquisas-judiciarias/justica-em-numeros/.

Acesso em: 17 maio 2020.

BRASIL. Lei $\mathrm{n}^{\circ}$ 5.172, de 25 de outubro de 1966. Código Tributário Nacional. Dispõe sobre o Sistema Tributário Nacional e institui normas gerais de direito tributário aplicáveis à União, Estados e Municípios. Diário Oficial da União. Brasília, 27 out. 1966. 
GOMES, Magno Federici; MARTÍNEZ LAZCANO, Alfonso Jaime; CARVALHO, Michele Alves de. O sistema Online Dispute Resolution em execução fiscal: arbitragem tributária e jurisdição sustentável

BRASIL. Lei $n^{\circ}$ 6.830, de 22 de setembro de 1980. Dispõe sobre a cobrança judicial da Dívida Ativa da Fazenda Pública, e dá outras providências. Diário Oficial da União, Brasília, 24 set. 1980.

BRASIL. Lei $\mathrm{n}^{\circ}$ 9.307, de 23 de setembro de 1996. Dispõe sobre a arbitragem. Diário Oficial da União, Brasília, 24 set. 1996.

BRASIL. Lei no 13.105, de 16 de março de 2015. Código de Processo Civil. Diário Oficial da União, Brasília, 17 mar. 2015. Disponível em:

http://www.planalto.gov.br/ccivil_03/_ato2015-2018/2015/lei/113105.htm. Acesso em 08 abr. 2020.

BRASIL. Lei ${ }^{\circ} 13.129$, de 26 de maio de 2015. Altera a Lei $n^{\circ} 9.307$, de 23 de setembro de 1996, e a Lei no 6.404, de 15 de dezembro de 1976, para ampliar o âmbito de aplicação da arbitragem e dispor sobre a escolha dos árbitros quando as partes recorrem a órgão arbitral, a interrupção da prescrição pela instituição da arbitragem, a concessão de tutelas cautelares e de urgência nos casos de arbitragem, a carta arbitral e a sentença arbitral, e revoga dispositivos da Lei no 9.307, de 23 de setembro de 1996. Diário Oficial da União, Brasília, 27 maio 2015. Disponível em: http://www.planalto.gov.br/ccivil_03/_Ato2015-2018/2015/Lei/L13129.htm. Acesso em: 18 maio. 2020.

BRASIL. Lei n ${ }^{\circ} 13.988$, de 14 de abril de 2020. Dispõe sobre a transação nas hipóteses que especifica; e altera as Leis nos 13.464, de 10 de julho de 2017, e 10.522, de 19 de julho de 2002. Diário Oficial da União, Brasília, 14 abr. 2020. Disponível em:

http://www.planalto.gov.br/ccivil_03/_ato2019-2022/2020/lei/113988.htm. Acesso em: 02 fev. 2021.

BRASIL. Ministério da Justiça. Indicadores Consumidor.gov.br. Brasília, 2020. Disponível em: https://www.consumidor.gov.br/pages/indicador/infografico/abrir\#minasgerais. Acesso em: 25 fev. 2020.

BRASIL. Projeto de Lei ${ }^{\circ} 4.257$, de 2019. Modifica a Lei $n^{\circ} 6.830$, de 22 de setembro de 1980, para instituir a execução fiscal administrativa e a arbitragem tributária, nas hipóteses que especifica. Senado Federal, Brasília, 2019. Disponível em:

https://www25.senado.leg.br/web/atividade/materias/-/materia/137914. Acesso em: 17 maio 2020.

BRASIL. Superior Tribunal de Justiça. Mandado de Segurança ${ }^{\circ}$ 11.308/DF. Relator: Luiz Fux. Diário de Justiça Eletrônico. Brasília, 09 de abril de 2008. Disponível em: https://stj.jusbrasil.com.br/jurisprudencia/601873/mandado-de-seguranca-ms-11308-df-20050212763-0. Acesso em: 18 maio 2020.

ESCOBAR, Marcelo. A arbitragem tributária no Brasil. São Paulo: Almedina, 2017.

GOMES, Magno Federici; CABRAL, Ana Luiza Novais; RIBEIRO, Sidiney Duarte. As plataformas de resoluções online de conflitos: novos paradigmas para a "desjudicialização" de litígios no Brasil. Revista Magister de Direito Civil e Processual Civil, Porto Alegre: Magister, n. 103, ano XVIII, p. 136-151, jul./ago. 2021. 
GOMES, Magno Federici; MARTÍnEZ LAZCANO, Alfonso Jaime; CARVALHO, Michele Alves de. O sistema Online Dispute Resolution em execução fiscal: arbitragem tributária e jurisdição sustentável

GOMES, Magno Federici; FERREIRA, Leandro José. A dimensão jurídico-política da sustentabilidade e o direito fundamental à razoável duração do procedimento. Revista do Direito, Santa Cruz do Sul, v. 2, no 52, p. 93-111, maio/set. 2017. Disponível em: http://dx.doi.org/10.17058/rdunisc.v2i52.8864. Acesso em: 17 abr. 2020.

KATSH, Ethan; RIFKIN, Janet; GAITENBY, Alan. E-Commerce, E-Disputes, and E-Dispute Resolution: In the Shadow of "eBay Law". Ohio State Journal on Dispute Resolution, Columbus, v. 15, no 3, 2000.

MENDONÇA, Priscila Faricelli. Arbitragem e transação tributárias. São Paulo: Gazeta Jurídica, 2014.

ONLINE Dispute Resolution (ODR) e a ruptura no ecossistema da resolução de disputas. AB2L, Rio de Janeiro, 2017. Disponível em: https://ab21.org.br/online-dispute-resolution-odre-ruptura-no-ecossistema-da-resolucao-de-disputas. Acesso em 20 abr. 2020.

PASSINATO, Ana Paula. Arbitragem tributária eletrônica no Brasil. In: UFSM. Anais do 5o Congresso Internacional Direito e Contemporaneidade: mídias e direitos da sociedade em rede. Santa Maria: UFSM, 2019. Disponível em: https://www.ufsm.br/cursos/posgraduacao/santa-maria/ppgd/congresso-direito-anais. Acesso em: 22 fev. 2020.

SUPREMO em números mostra explosão de ações de consumidor. Valor Econômico, São Paulo, 22 ago. 2013. Disponível em: http://www.valor.com.br/legislacao/3243360/supremoem-numeros-mostra-explosao-de-acoes-de-consumidor. Acesso em: 22 fev. 2020. 